\title{
Robustness of large-span timber roof structures - Structural aspects
}

\author{
Philipp Dietsch \\ Technische Universität München, Arcisstr. 21, 80333 Munich, Germany
}

\section{A R T I C L E I N F O}

Article history:

Available online $\mathrm{xxxx}$

\section{Keywords:}

Timber

Structural systems

Secondary structures

Robustness

Determinate structures

Redundant structures

Local effects

Global effects

Human errors

Deterministic analysis

Probabilistic analysis

\begin{abstract}
A B S T R A C T
Design rules for robustness require insensitivity to local failure and the prevention of progressive collapse. This is often verified by applying the load case "removal of a limited part of the structure". This paper will evaluate typical structural systems for large-span timber roof structures against these requirements, comparing the results against typical reasons for damages and failures. Applying the finding that most failures of timber structures are not caused by random occurtences or local defects, but by global (repetitive) defects (e.g. from systematic mistakes), it is shown that the objective of load transfer - often mentioned as preferable - should be critically analysed for such structures. Based on these findings, proposals for structural systems and details towards a robust design of large-span timber roof structures are given.
\end{abstract}

(c) 2011 Published by Elsevier Ltd

\section{Introduction}

\subsection{Robustness requirements for timber structures}

The requirement for a robust structure is often defined as a structure being "designed in such a way that it will not be damaged by events like fire, explosions, impact or consequences of human errors, to an extent disproportionate to the original cause" [1]. A structure shall be insensitive to local failure (disproportionate collapse), thereby including the design against progressive collapse. This is a property of the structure itself, independent of possible causes of initial local failure. There are several approaches to demonstrate a robust design, e.g. given in [2]. One of these approaches is to demonstrate that a load case "removal of a limited part of the structure" will not lead to extensive failure.

\subsection{Structural systems for large-span timber roof structures}

Although there is a multitude of possibilities for structural systems (see e.g. [3]), most large-span timber structures as roof structures of arenas or halls are often composed of a determinate primary structure carrying a secondary structure in the form of purlins; see Figs. 1 and 2.

The primary structure often consists of single-span members, e.g. pitched cambered glulam beams, trussed beams or three

E-mail address: dietsch@bv.tum.de. hinged frames. The purlins can be realized as simply supported beams (a), continuous beams (b), gerber beams (c) and lap-jointed purlins (d); see Fig. 3.

Evaluatîng purlin systems from a structural perspective will highlight continuous systems due to their lowered maximum bending moments, enabling the realization of larger spans $e$ at given spacings $e_{p}$ and cross-sections. Due to this and due to the acceleration of the construction process, purlin systems today are often realized by continuous systems like lap-jointed purlins.

Design rules for robustness require insensitivity to local failure and the prevention of progressive collapse. This is often verified by applying the load case "removal of a limited part of the structure". In the following, typical purlin systems for timber roof structures will be evaluated against these robustness requirements.

\section{Robustness evaluation of typical purlin systems in large- span timber roof structures}

\subsection{Evaluated system}

The evaluation of typical purlin systems utilized for timber roof structures (as shown in Fig. 3) with respect to their influence on the robustness of the whole structural system is realized by a comparison of how the removal of a limited part of the structure will affect the remaining structure. This is supported by comparative deterministic calculations on the exemplary roof geometry given in Fig. 1. Since the detailed description of the evaluated system as well as the full presentation of the results would lead to an excess size of this publication, only the key results 
P. Dietsch / Engineering Structures $x x(x x x x) x x x-x x x$

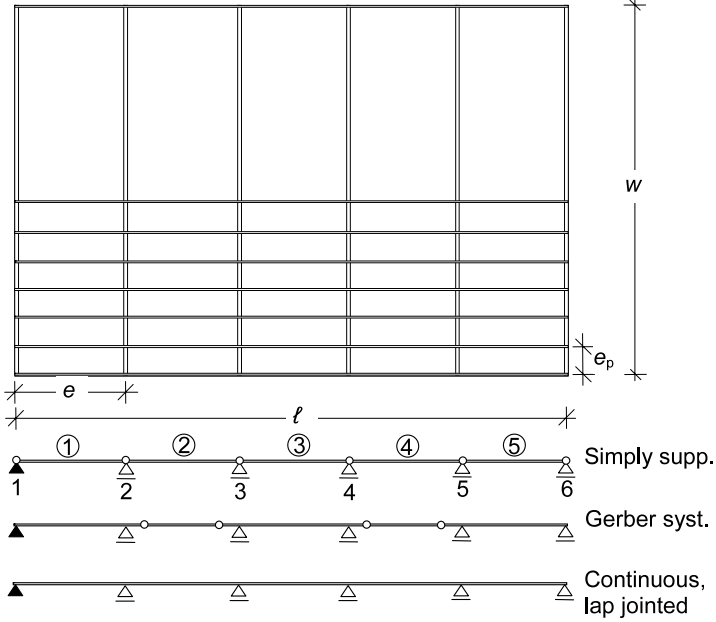

Fig. 1. Schematic layout of evaluated structure and possible purlin systems.

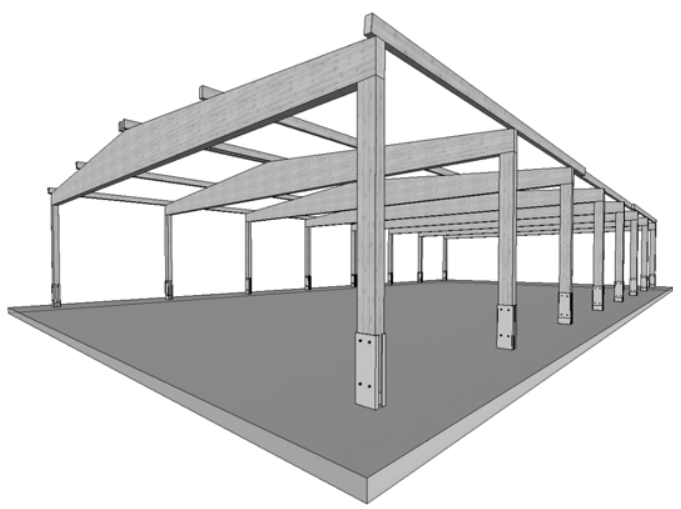

Fig. 2. Isometric sketch of structure comparable to evaluated system.
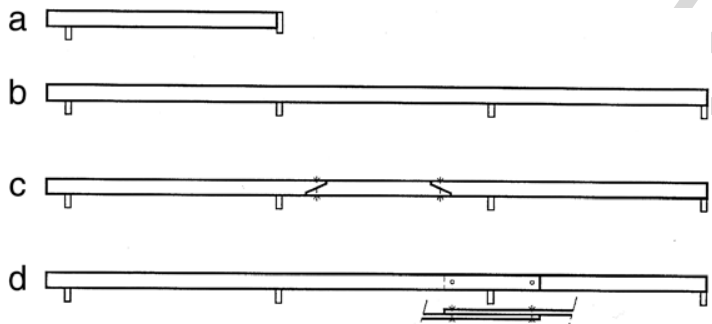

Fig. 3. Typical purlin systems. Source: From [4].

Table 1

"Removal of a limited part of the structure" - failure cases (here: gerber system).

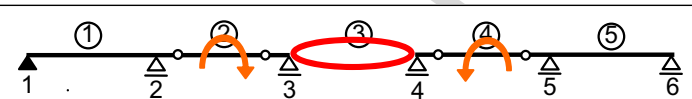

(a) Removal of a purlin between two supports (equivalent to the failure/rupture of one purlin).

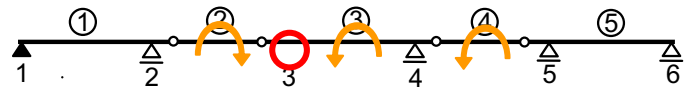

(b) Removal of one support (equivalent to the failure of one main beam).

will be given. The reader is therefore kindly referred to the detailed description given in [5]. Typically, two cases are evaluated (see Table 1).

The evaluation is based on two aspects:

a. Damaged area.

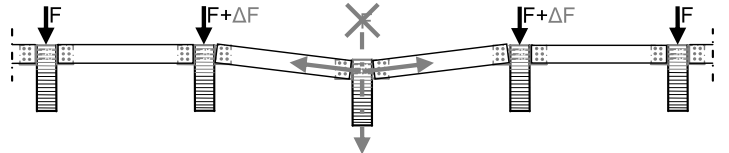

Fig. 4. Example of purlin acting as tie member in the case of failing main member, "hinging" itself into the remaining members (to be avoided).

b. Load transfer respectively additional load on the remaining members.

\subsection{Damaged area}

In the case of simply supported purlins as well as continuous and lap-jointed purlin systems - failure of one purlin will result in locar damage (no other field than the one covered by the failing member will fail due to system instability). The failure of one purlin in a gerber system will - because of system instability - in the worst case result in the additional failure of the two adjacent purlins. This extends the damaged area by $200 \%$, compared to the area covered by the failed member (see Table 1 ).

In the case of one main member failing, simply supported purlins as well as continuous and lap-jointed purlin systems result in the failure of the adjacent purlins (damage restricted to two fields). In the case of gerber beams, the failure of one main member will in the worst case result in the failure of 3 purlins, thereby extending the damaged area by $50 \%$ (see Table 1 ).

\subsection{Load transfer/additional load on remaining members}

A determinate purlin system, e.g. realized by simply supported purlins has the advantage that failure of one member will not result in substantial overloading of other than the failing members. To achieve that, it is important to design the connections in such a way, that they will not transfer large additional loads in the case of failure (failing member "hinging" itself into the remaining members; see Fig. 4). This fact is further treated in Section 4. Likewise, the remaining purlins in gerber systems are subjected to a comparatively small stress increase after failure of a purlin or main member.

Redundant systems as continuous or lap-jointed purlin systems are more critical in that aspect. A failing purlin will increase the bending stress in the remaining purlin system as well as the local loads on the main beams by up to $50 \%$. This will usually not be critical. A failing main member, hinging itself into the purlin system results in a much larger increase of the stresses in the purlins due to the doubled span. In the exemplary system evaluated (see Fig. 1 and [5]), this increase theoretically reaches $475 \%$ resp. $520 \%$. If the purlins shall be designed to enable load distribution, the realizable distance between the main members or the purlins would decrease significantly, even if a system factor $k_{\text {sys }}=1.1$ permitted by EN 1995-1-1 [6] is included.

A failing main member, hinging itself into a continuous secondary system, will result in an additional loading of the remaining main members, depending on the remaining strength and stiffness of the purlin system (achievable utilization factor before rupture of the purlins). In the exemplary system evaluated, this increase could reach 82\%. Since EN 1990 [1] permits the application of the accidental load case for situations after an accidental event like local failure, this will most probably not result in utilization factors $\eta>1.0$.

In the case of failure due to local damage, such utilization factors will most probably not become critical. But in the case of a higher correlation of damages (all members suffering from the same damage due to global effects), it becomes evident that a structure containing systematic mistakes will not be able to withstand a large load increase due to load distribution from one failing member, meaning it is more fragile to collapse progressively. This is further demonstrated in the following sections. 
Table 2

Examples for types of damaging effects and their extent.

Local effects - local failures, e.g.

- Local deterioration of element from e.g. local water ingress

-Local weakening of element from e.g. holes

-Local overloading from e.g. local snow accumulation
Global effects, e.g.

- Global weakening of structural elements due to systematic mistakes.

- Global deterioration of elements from e.g. wrong assumption of ambient climate

- Global overloading from e.g. addition of green roof without structural verification

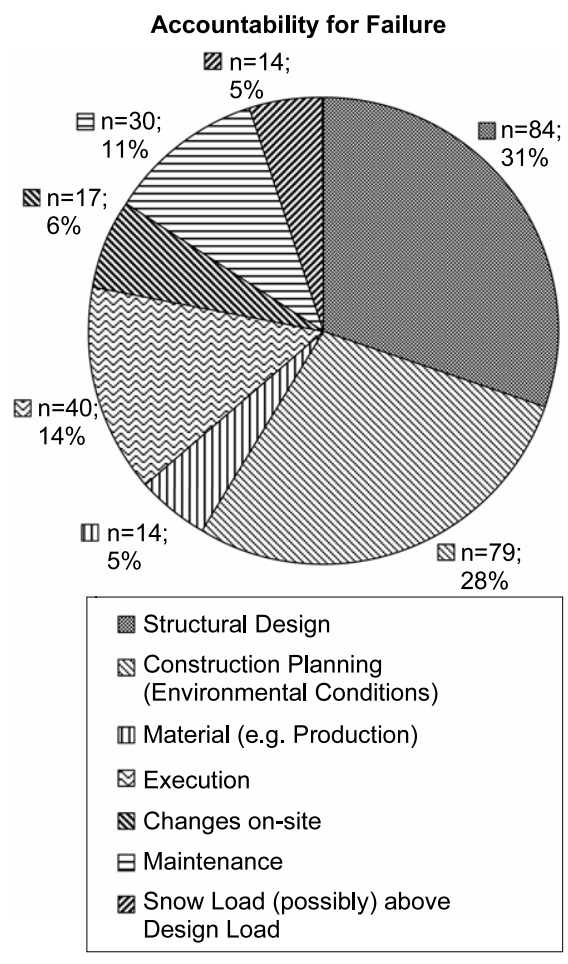

Fig. 5. Accountabilities for failures from an evaluation of 214 cases of failed timber structures [9].

\subsection{Local/global effects in timber structures}

Failures in structures can range from local failures of structural elements to total (global) collapse. The extent of failure also depends on the type of damaging effects which can be of local nature (e.g. local deterioration from local water ingress) or global nature (e.g. global weakening of elements due to systematic mistakes). Table 2 gives examples for both types of effects which are common in timber structures.

Most robustness strategies given in codes and literature are based on the prevention of a localized effect of short duration (e.g. explosion or impact) leading to a disproportionate collapse of the structure. The given strategies (e.g. load distribution) will also be beneficial for other types of local effects, as given in Table 2 .

On the other hand, numerous studies on failures in timber structures e.g. [7-9] have shown, that the correlation of failures or developing weak spots is larger than assumed, meaning global damage from systematic (repetitive) mistakes is much more common than local damage (e.g. local overloading from local snow accumulation) or statistically random occurrences (e.g. low material strength). The reason is that timber structures (primary and secondary structures) are usually composed of repetitive elements which are connected by analogical construction principles. This systematic implies that a mistake, made during the planning or construction phase, will most likely repeat itself in all identical elements. Fig. 5 shall illustrate above given statement.

A project carried out at the Chair for Timber Structures and Building Construction, evaluating 214 cases of failed timber structures [9], depicts the accountabilities for evaluated failures as shown in Fig. 5. It can be concluded that $70 \%$ of the errors (design, planning and maintenance) will - with an utmost probability have a global effect while the remaining $30 \%$ of failures can either result in global or local damages. These numbers are comparable with the data given in [10], comparing multiple studies on failures in structures of all building materials. That study by Ellingwood reveals an average of $45 \%$ failures due to errors in design and planning, $38 \%$ due to construction errors and $17 \%$ due to errors in the utilization phase (maintenance).

\subsection{Discussion of robustness strategies}

Evaluating purlin systems from a structural perspective will highlight continuous systems due to their lowered maximum bending moments, enabling the realization of larger spacings $e_{p}$ at given span and cross-section. Due to this and due to the acceleration of the construction process, purlin systems today are often realized by continuous systems like lap-jointed beams.

The evaluation from a robustness perspective reveals more debatable results. Continuous systems (due to their redundancy and higher stiffness) will result in an increased load transfer in the case of failure of one structural member. Many publications on robustness mention the redistribution of loads as preferable, which is true in the case of local effects, e.g. local deterioration of element from local water ingress.

Nevertheless, as recent studies have revealed, most failures of timber structures are not caused by local defects but by global defects from systematic mistakes such as global weakening of structural elements due to systematic (repetitive) mistakes. Structures suffering from global damaging effects are not able to withstand a large load transfer from neighbour members and will therefore be more prone to progressive collapse. This idea is supported in [11] stating that the "alternate load path" approach (realized by e.g. parallel systems) may "in certain circumstances not prevent but rather promote collapse progression". Hence, the idea of compartmentalization is introduced which is realized by a deliberate reduction of continuity at chosen compartment borders. For the systems discussed, this approach might be preferable, if the strength and/or stiffness required for the formation of an alternate load path cannot be guaranteed in case of failure of one element.

In summary it can be stated that there is no strategy for the structural designer, which ensures robustness in all cases. When deciding on a robustness strategy one has to consider different scenarios. The major difference is whether the cause of failure is likely to be a systematic (mostly human) error or an unforeseeable (mostly local) incident. This is subsumed in Table 3 which lists possible robustness approaches with regard types of damaging effects.

Experience tells that human errors are by far the most common cause of failure. In order to reduce the risk of collapse and in particular progressive collapse, it is crucial to reduce the number of human errors by e.g. enhanced quality control. Against this background, it should be discussed if and how the intensity of quality control should be made dependent upon the number of identical elements used in a structure (Vogel T., pers. comm.). Only if systematic errors are considerably reduced, it would be possible to choose an unambiguously beneficial robustness strategy. 
Table 3

Preferable robustness approach depending on the type of damaging effect; see Table 2.

\begin{tabular}{|c|c|}
\hline Local effects - local failures & Global effects \\
\hline $\begin{array}{l}\text { - Redistribution of loads to adjacent (undamaged) } \\
\text { elements by e.g. redundant secondary system }\end{array}$ & $\begin{array}{l}\text { - Limiting failure to local level by e.g. determinate secondary systems with "weak/flexible" connections } \\
\text { - Compartmentalization/Segmentation }\end{array}$ \\
\hline
\end{tabular}

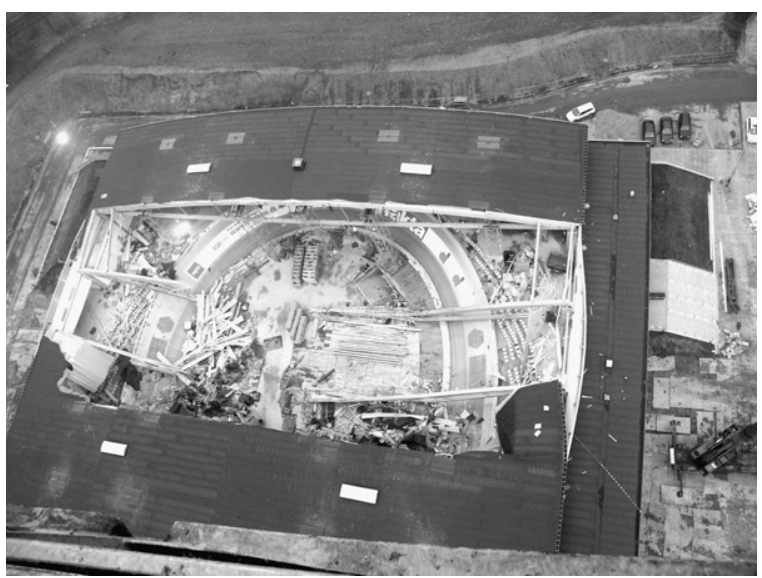

Fig. 6. Top view on Siemens-Arena Ballerup, Denmark, collapse of 2 out of 12 main trusses (Photo: Peter M. Thorup).

\section{Examples}

Two cases of failed structures, both featuring systematic errors in design and construction, shall serve as examples of different design strategies for large-span timber structures and their consequence for robustness. Both structures and the effects leading to their failure are described in detail in [12] this issue.

\subsection{Siemens-Arena}

The Siemens-Arena (described in detail in [13]) suffered from gross errors in the structural design, reducing the load-carrying capacity of the heel joint of the fish-shaped truss to $25 \%-30 \%$ of its required strength. Due to this, two of the $72 \mathrm{~m}$ long trusses collapsed without warning and under very low variable loads, shortly after the opening of the arena (see Fig. 6). During design it was decided "that the $12 \mathrm{~m}$ long purlins between the trusses should only be moderately fastened to the trusses, such that a failure of one truss would not initiate progressive collapse. The chosen robustness strategy with weak purlins proved to work fairly well as "only" two of the 12 trusses collapsed. Considering that all trusses had a much lower strength than required it might be fair to conclude that the extent of the collapse was not disproportionate to the cause.

\subsection{Bad Reichenhall Ice-Arena}

The Bad Reichenhall ice-arena (described in detail in [14]), featuring timber box-girders with lateral web boards made from so-called "Kämpf web boards", suffered from multiple errors and defects, including cumulative degradation processes in the gluelines and finger joints due to the humidity exposure over the years. Due to fact that the secondary system, which was realized as a K-bracing to also function against lateral torsional buckling, was not only strong but also very stiff, the loads were shifted from the girder that failed first to the neighbouring girders. Since these girders suffered from the same errors and degradation processes as the girder failing first, they could not sustain the additional load. Consequently, this developed into a progressive collapse of the whole roof structure under a large but not exceptional snow load, which realized within seconds (see Fig. 7).

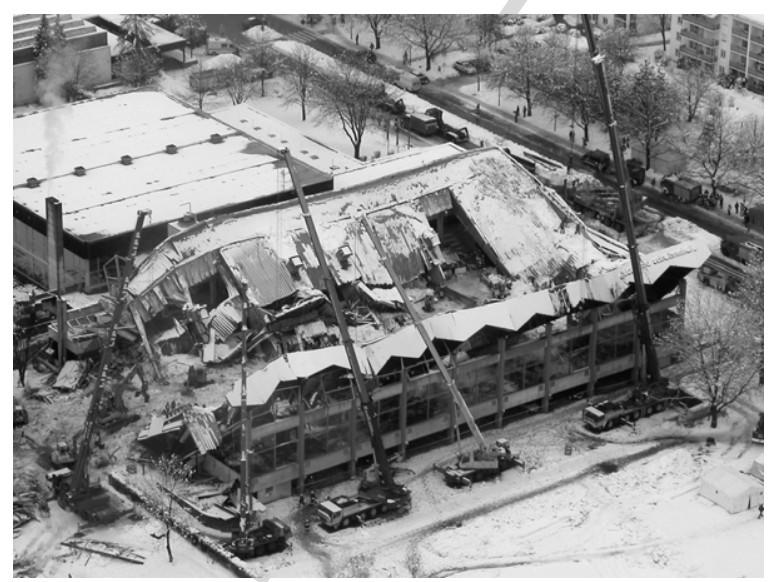

Fig. 7. Top view on Bad Reichenhall Ice-Arena after progressive collapse of all main girders (Photo: LKA Bayern).

\subsection{Conclusions}

The Siemens-Arena was a statically determinate structure, whereas $\wedge^{\wedge}$ the Bad Reichenhall Ice-Arena was a highly statically indeterminate structure, with a very stiff secondary system. These two cases demonstrate that redundancy on its own is not suitable for limiting the consequence of failures due to systematic errors. Compartmentalization/segmentation, ensuring that a collapse does not become progressive appears to be necessary. On the other hand would redundancy on a more local scale be desirable because it can minimize the consequence of random errors. Such redundant systems must be designed in a way that it becomes evident if redistribution of loads has taken place, e.g. by visible deformations.

\section{Proposals towards designing for robustness in large-span timber roof structures}

Robustness strategies can be ambiguous, as outlined in Section 2 , since the best strategy depends on the failure scenario. In this section, some ideas are outlined with the aim to reduce failures of primary structural elements while decreasing the possibility of a progressive collapse in the case of an element failing. For this reflection, seismic situations have not been considered since they oftentimes require a different treatment. The same holds for multistorey timber buildings for which different approaches should be used. Instructions for this type of buildings are given in EN 19911-7, Annex A [15]. They include considerations on the geometry of the building and the interaction of the building components as well as the provision of internal and peripheral horizontal ties in both orthogonal directions plus vertical ties which are provided continuously from the lowest to the highest level featuring appropriate means of anchoring the floors to the walls. As a matter of course should the building components be checked for the effect of removal. The ideas presented in the following are solely based on structural considerations, not on the objective of efficiency and cost-effectiveness.

Whereas historical timber roof structures were oftentimes realized as highly indeterminate systems, did the developments in timber engineering lead to the fact that most large-span timber 


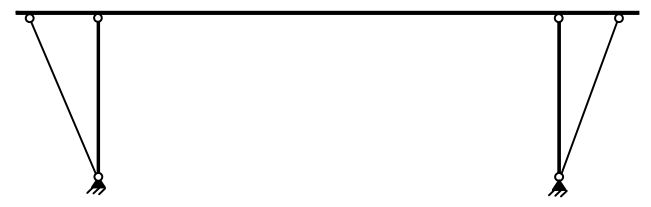

Fig. 8. Indeterminate frame system with V-shaped frame corner.

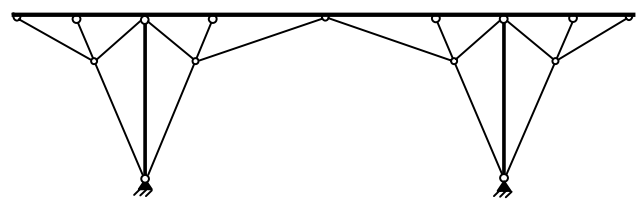

Fig. 9. Indeterminate system with V-shaped column and struts.

structures today are realized with a statically determinate primary structure (e.g. single-span beams), carrying a statically indeterminate secondary structure.

From the background of the statements given in Section 2, should this scenario of redundancy be reversed, meaning that primary elements should become more redundant while secondary structures should be designed as determinate systems to achieve the objective of compartmentalization. Nevertheless could redundancy on a local scale be desirable because it can minimize the consequence of random errors. Such redundant systems must be designed in a way that it becomes evident if redistribution of loads has taken place, e.g. by visible deformations. While it is obvious that all elements in the proposals given shall be verified according to the ultimate limit state design situation, it might be worthwhile stating that EN 1990 [1] permits the application of the accidental load case for situations after an accidental event like local failure which can be affiliated with the load case "removal of a limited part of the structure".

The fact that most structures are realized with identical, repetitive elements forming statically determinate main structures should activate considerations on how quality control could be adapted accordingly. An alternative approach would be to introduce diversity and indeterminacy into the structure, e.g. by designing a structure with many different elements, thereby avoiding too much symmetry and repetition and facilitating redistribution of loads between the diverse elements. In spite of these advantages will the aim to introduce diversity and indeterminacy into a structure result in higher demands in terms of design, planning, manufacture and execution, and thereby higher costs.

\subsection{Primary structures}

Although most primary systems in timber structures are statically determinate systems, there are a few possibilities to realize redundant primary systems. Amongst the most typical statically indeterminate structural systems for timber roof structures are frame systems, oftentimes realized with V-shaped columns; see Fig. 8. This approach can be refined by integrating struts a $\hat{s}$ shown in Fig. 9.

Another possibility to increase redundancy of primary structural elements is to introduce internal indeterminacy. Examples of this are trusses with diagonal cross members or beams which are trussed with sag rods (see Fig. 10). For such systems it seems feasible to consider the failure of one structural element (e.g. the steel rods), designing the remaining elements to withstand the stress resultants in the changed structural system in the accidental load case. This would, however, usually imply that the key elements need to be over-designed in the ULS.

Since timber is a highly anisotropic material, structural elements are sometimes reinforced with e.g. pre-drilled, screwed-in

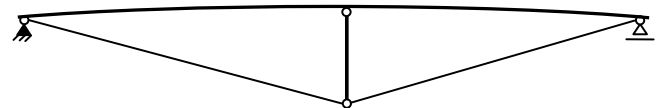

Fig. 10. Example of system with internal indeterminacy: beam trussed with sag rod.

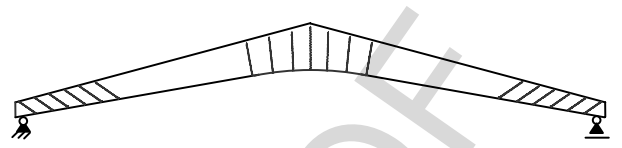

Fig. 11. Example of a pitched cambered beam with reinforcements

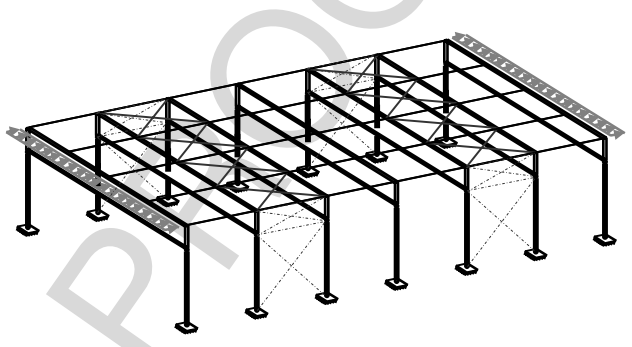

Fig. 12. Exemplary structural system with purlins performing as part of the bracing system.

rods to compensate for low strength properties, e.g. tension perpendicular to grain or shear strength. Due to the fact that both failure mechanisms are very brittle, meaning that the deformations in linear-elastic range are very small, such reinforcements might not be able to activate their full load-carrying capacity in the undamaged state (especially for shear reinforcements with screwedin rods). But even though the additional load-carrying capacity due to the reinforcing elements might be relatively low in the undamaged state, should they be regarded as beneficial. The reason is, that they can be designed to carry the full shear or tension perpendicular to grain stresses in the damaged state, meaning they prevent a full separation of the upper and lower parts of the beam in the case of a local separation (crack) due to over-stressing. Thereby they introduce redundancy since they represent a second barrier against brittle failure mechanisms (Fig. 11).

\subsection{Secondary structures}

Typical purlin systems for timber structures have to fulfil two requirements:

a. to carry the vertical loads from the roof structure (e.g. selfweight and snow) and to transfer them to the primary structural elements;

b. to perform as part of the bracing system, transferring the horizontal loads (stability and wind loads) to the vertical bracing system (see Fig. 12).

This dual function causes the main difficulties when considering robustness and the objective of realizing compartmentalization. To obtain functionality as bracing against wind loads and lateral torsional buckling of the primary members, the purlin systems are realized to transfer horizontal (axial) loads in tension and compression. This implies that, in the case of one main member failing, the purlin systems will develop into a tie member, thereby transferring the vertical loads from the failing member to the adjacent members (see Fig. 4 in Section 2.3). It should be noticed that robustness requires at least two vertical bracing elements, one near to each end of the building. This will ensure that the remaining parts of the building are still stabilized after the failure of one main member. 


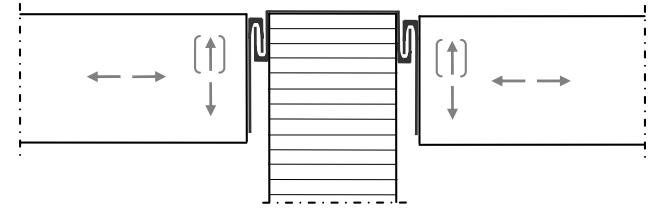

Fig. 13. Connection to transfer horizontal and vertical loads, potentially enabling detachment in case of failure.

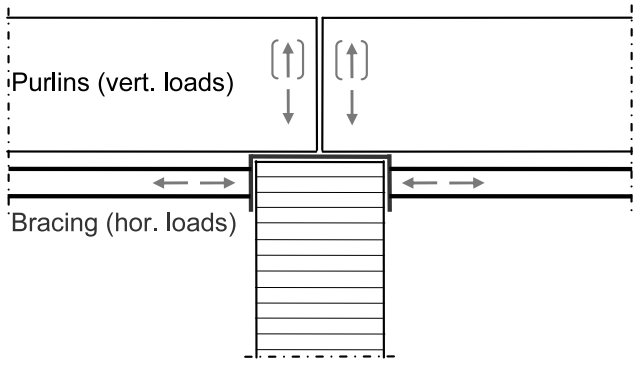

Fig. 14. Separation of load bearing structure for horizontal and vertical loads, enabling detachment in case of failure.

\subsection{Detailing of connections with respect to robustness}

A first design approach with regard to the challenges illustrated in the previous section would be to differentiate between the purlins according to their functions since not every purlin has to act as part of the bracing system. This means that purlins which are not part of the bracing system should be designed as to not transfer axial (horizontal loads) while purlins that act supplementary as part of the bracing system should not "hinge" themselves into the remaining main members in case of failure. The latter could be achieved by not "over-designing" the connections between the determinate purlins for axial forces, meaning that the purlins would only form a tie member until the system reaches the axial design load from horizontal loads. This could be achieved by e.g. matching the amount of nails used in hangers to these forces.

Another connection type which would enable this and potentially lead to a detachment of the purlin system and the main member in case of failure is sketched in Fig. 13. Many producers of connectors offer systems which feature illustrated mechanisms since such connector types are also known to decrease assembly time. For such cases in which vertical loads should basically only be transferable in compression it is important to check if lifting forces like wind-suction are compensated by the self-weight of the roof. If this is not the case (e.g. in edge regions), these lifting forces have to be locally anchored whereby the anchoring device should adhere to the mentioned requirements (easy detachment in case of failure).

It is self-evident that the roof cladding be constructed so as not to develop into a tie member in the case of failure. While it might be worth considering a roof cladding which can carry the loads on a failing purlin to other purlins, it should definitely not support load transfer in the case of a failing main member.

Pushing these ideas further it seems plausible to consider a clear separation of both functions stated above. This would result in a purlin system, designed to only transfer vertical loads and one separate bracing system to carry all horizontal loads. A possible layout of this detail is sketched in Fig. 14.

The supports of the purlins on the main members could then be designed to only carry vertical loads, while simply a slight horizontal fastening would be needed to secure their position. The bracing system would still be designed to transfer horizontal loads in tension and compression but - due to the separation of both systems - would not transfer any vertical loads to the neighbouring beams in the case of one main member failing. Nevertheless

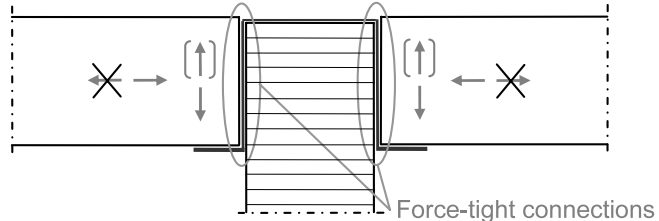

Fig. 15. Connection to transfer axial compression forces and vertical loads, enabling detachment in case of failure.

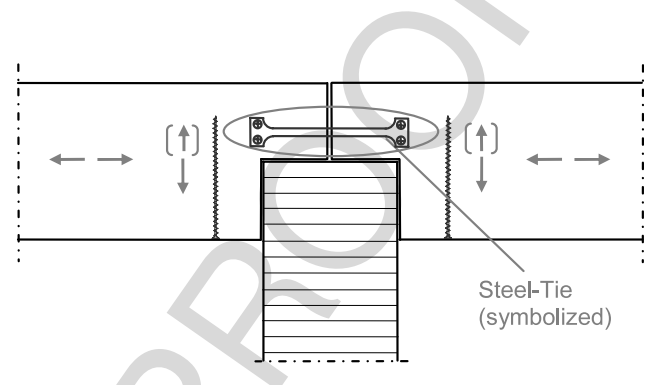

Fig. 16. Connection to transfer axial tension and compression forces and vertical loads, enabling detachment in case of failure.

can such a design only be fully beneficial if easy detachment of main member and bracing system is enabled (as indicated by the channel section, only horizontally stabilizing the main beam) and the purlins and bracing elements are not placed within the same plane. Although only bracing elements perpendicular to the main member are sketched in Fig. 14, it is self-evident that cross bracing is needed to transfer the horizontal loads to the vertical bracing elements. Load transfer in case of failure will be more pronounced between two primary members adjacent to a horizontal cross bracing, making these members key elements which should be given special consideration during design.

Modifying the above given possibilities, one could consider a bracing system which is designed to only carry axial (horizontal) loads in compression, meaning that horizontal loads could only be transferred unidirectional as shown in Fig. 15. Following the requirement of redundancy this would mean that at least two bracing systems be realized for each direction of load. Such a system needs exact execution to obtain force-tight connections. Nevertheless, due to the necessary lengths of load transfer and possible problems in meeting the horizontal deflection limits, such a system seems less feasible.

The addition of small steel-ties between the purlins would permit the two-directional transfer of horizontal loads; see Fig. 16. The steel-ties need to be designed for axial tension forces. But if they are not "over-designed", they should fail of as soon as significant rotation of one of the purlins starts.

A system, comparable to Fig. 13, which enabled easy detachment between secondary members, hangers and main members, was applied in the roof structure of an exhibition centre. When one main beam collapsed due to the corrosion failure of its appendant steel suspension cable, did the purlins not develop into tie members but developed hinges at the supports, limiting the failure to one field (see Fig. 17).

A final alternative to realize connections between the primary beams and the purlins which only transfer vertical forces, thereby enabling easy detachment in the case of failure of one element is to design the primary beams as internally stable against lateral torsional buckling, also being capable to transfer external horizontal loads (e.g. wind loads). This is only achievable if the primary beams be designed less slender or with a T-section as sketched in Fig. 18. 


\section{ARTICLE IN PRESS}

P. Dietsch / Engineering Structures $x x(x x x x) x x x-x x x$

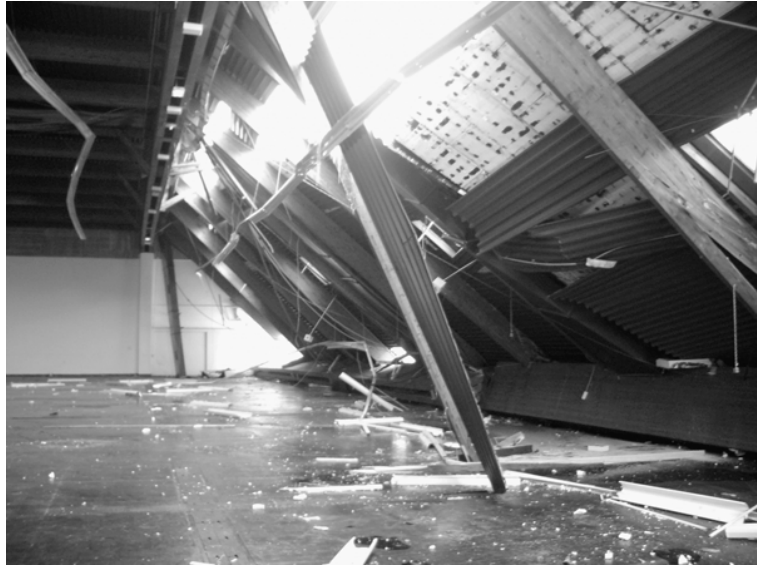

Fig. 17. Exhibition centre, failure of one main beam, development of hinges at supports of purlins [Photo: MPA BAU, TUM].

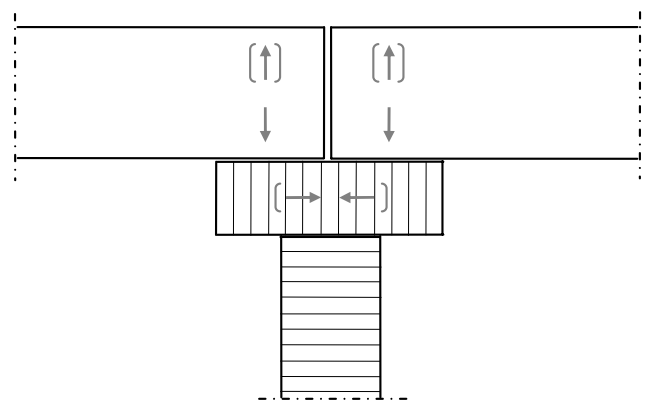

Fig. 18. Primary beam with cross-section to enable internal stability against lateral torsional buckling, also capable to transfer external horizontal loads (e.g. wind loads).

\section{Outlook}

It is the belief of the author that given statements are valid for the majority of large-span timber roof structures. The numerical values given in Section 2 are nevertheless constricted to the example presented in [5]. To put this comparison on a broader foundation, also considering a probabilistic approach and accounting for both, random and systematic errors, a research project "riskbased assessment of robustness and collapse behaviour of secondary structures in large-span timber structures" is carried out in collaboration with the Engineering Risk Analysis Group at the Technische Universität München. First analyses were performed by Simona Miraglia under the supervision of Prof. Daniel Straub. An in-depth description of the approach and presentation of the results will be given in [16]. First results from a model of different purlin systems (which assumes that the primary beams are intact) indicate that statically indeterminate purlin systems feature higher system reliability but also higher consequences of failure.
These studies are performed as part of European research efforts on the understanding of robustness of timber structures. Future steps in these efforts involve an evaluation of typical structural components and connection details with respect to:

- possible failure mechanisms and probability of occurrence

- load transfer in the case of failure

- consequence of failure

- load-carrying capacity of components and connections and its variation

- ductility of components and connections and uncertainty of occurrence of ductile failure

\section{Acknowledgement}

Part of this research has been performed in the framework of COST Action E55 "Modelling of the Performance of Timber Structures", Working Group 3 "Robustness of Systems". All ideas and comments from the members of the COST action, especially Jørgen Munch-Andersen and John Dalsgaard Sørensen, towards this work are greatly appreciated. Gratitude is extended to the COST Office for funding the working group meetings.

\section{References}

[1] EN 1990:2002-04. Eurocode: basis of structural design. CEN; 2002.

[2] DS-INF 146:2003. Robustness - background and principles - information, Danish Standards Association; 2003.

[3] Herzog T, Natterer J, Volz M. Timber construction manual. Architecture: Birkhäuser; 2000.

[4] Short C. Purlins. In: timber engineering STEP 2 - design, details and structural systems. Centrum Hout. Netherlands; 1995, p. E3/1-E3/5.

[5] Dietsch P, Winter S. Robustness of secondary structures in wide-span Timber Structures. In: Proceedings 11th world conference on timber engineering (WCTE). Riva del Garda. Italy; (June 20-24), 2010.

[6] EN 1995-1-1:2004-11. Eurocode 5: design of timber structures - part 1-1: general - common rules and rules for buildings. CEN; 2004.

[7] Frese M, BlaßHJ. Statistical analysis of failures in timber hall structures investigation area Germany, This issue.

[8] Frühwald E, Serrano E, Toratti T, Emilsson A, Thelandersson S. Design of safe timber structures - how can we learn from structural failures in concrete, steel and timber? Report TVBK-3053. Div. of Struct. Eng. Lund University; 2007.

[9] Dietsch P, Winter S. Assessment of the structural reliability of all wide span timber structures under the responsibility of the city of munich. In: Proceedings 33rd IABSE symposium. Bangkok, (Thailand); September 9-11, 2009.

[10] Ellingwood B. Design and construction error effects on structural reliability. J. Struct. Eng. 1987;2:409-22.

[11] Starossek U. Progressive collapse of structures: nomenclature and procedures. Struct. Eng. Int. 2006;2:113-7.

[12] Munch-Andersen J, Dietsch P. Robustness of large-span timber roof structures - two examples. This issue.

[13] Hansson M, Larsen HJ. Recent failures in glulam structures and their causes. Eng. Failure Anal. 2005;12(5):808-18.

[14] Winter S, Kreuzinger $H$. The bad Reichenhall Ice-Arena collapse and the necessary consequences for wide span timber structures. In: Proceedings 10th world conference on timber engineering. Miyazaki, (Japan); 2008.

[15] EN 1991-1-7:2006. Eurocode 1: Actions on structures - General actions Accidental actions. CEN; 2006.

[16] Miraglia S, Dietsch P, Straub D. Comparative risk assessment of secondary structures in wide-span timber structures. In: Proceedings international conference on applications of statistics and probability in civil engineering (ICASP 11). Zürich, (Switzerland); August 1-4, 2011 (in press).

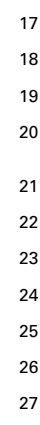

